\title{
Thin bed responses and correction methods for cased hole density logging
}

\author{
Wu Wensheng ${ }^{*}$ and Zhang Yuling ${ }^{2}$ \\ ${ }^{1}$ State Key Laboratory of Petroleum Resource and Prospecting, China University of Petroleum, Beijing 102249, China \\ ${ }^{2}$ China National Logging Corporation, CNPC, Beijing 100101, China
}

\begin{abstract}
The study of the thin bed responses and correction methods in cased hole density logging can provide a theoretical basis for research to improve data processing methods. By using the Monte Carlo program MCNP, the change of detector count from thin beds with the vertical depth was calculated at different casing thicknesses. The calculation showed that with the low density thin bed moving upward, detector count first increased to a maximum then decreased. The responses of a thin bed with a high density were opposite to those of a thin bed with a low density. The change curve was symmetrical, and the maximums or minimums appeared at the midpoint between the detector and source. Besides, detector count increased with increasing thin bed thickness. At a specific thin bed thickness, further increase of thin bed thickness resulted in a slow increase of detector count then the count rate leveled off. In actual logging, the influence of adjacent formations on density log measurements can be ignored. Finally, based on numerical simulation correction methods for the dual influence of casing and thin beds are discussed.
\end{abstract}

Key words: Density logging in cased hole, thin bed response, casing, MCNP program, correcting

\section{Introduction}

Over the past several years, logging methods for open hole formation evaluation have been used in cased holes (Bellman et al, 2003; Tan et al, 2003; Li et al, 2006; Qiao and Che, 2005; Shi et al, 2006; Luo et al, 2006; Zhou et al, 2007). A typical example in radioactive logging is cased hole litho-density logging. It can provide formation evaluation parameters for holes that have weak stability before being cased, and provide porosity data for cased holes without porosity data or for old wells with bad data quality. Furthermore, it can identify gas beds and monitor reservoir dynamics in cased holes (Cosentine and Spotti, 1992).

Using the Monte Carlo Neutron and Photo Transport Code (MCNP) (Wolcott and Vittachi, 1994; Quint, 1999), this paper focuses on the thin bed responses and correction methods for density logging in cased holes with the Slim Array LithoDensity Tool (SLDT) of the Schlumberger Company (Stoller et al, 1997; Moake, 1998; Ellis et al, 2004). In this paper, the dots in figures represent calculation results and the curves in figures represent fitting results.

\section{Calculation model}

Considering the actual conditions, the model is designed to be semi-cylindrical for calculation convenience (Wu and Huang, 2004; Wu and Xiao, 2007a; 2007b). Fig. 1 shows the longitudinal and lateral sections of the model. In the model,

*Corresponding author. email: wwsheng@yahoo.com.cn Received May 15, 2008 the formation thickness is $225 \mathrm{~cm}$ and the formation radius is from $10 \mathrm{~cm}$ to $43 \mathrm{~cm}$. The logging tool, which has a ${ }^{137} \mathrm{Cs}$ point source emitting gamma rays of $0.662 \mathrm{MeV}$, is placed against the borehole wall. The semi-cylindrical space between source and detector and above the detector is filled with ideal shielding material, whose thickness changes with the spacing. The space outside the model is also filled with shielding material. A point detector tallies the flux spectrum of photons with energy of above $0.15 \mathrm{MeV}$. The variance reducing techniques have been applied to Monte Carlo simulation without considering the detector effect. Relative calculation error of photon count is limited to $1 \%$.
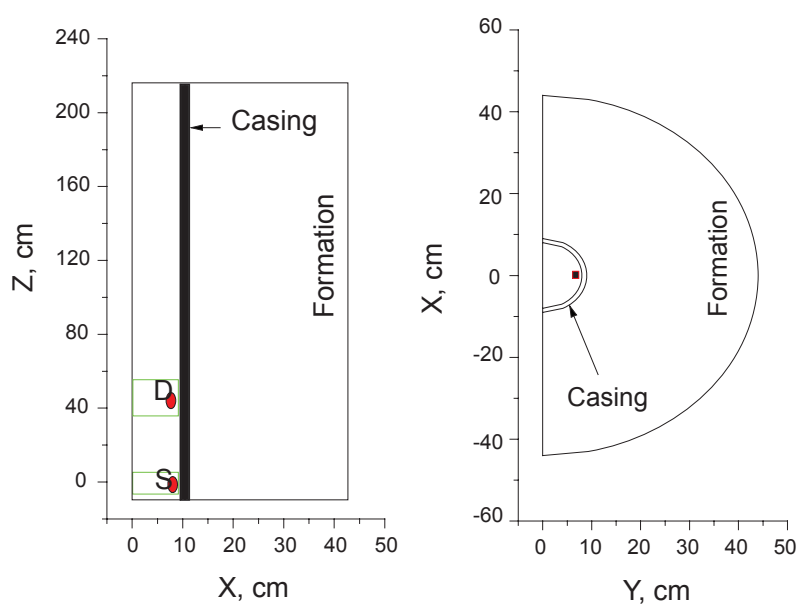

Fig. 1 Calculation model (D: detector; S: source) 


\section{Thin bed responses}

\subsection{Responses of thin bed location}

The calculation method is as follows. Wall rock is pure limestone with porosity of zero and density of $2.710 \mathrm{~g} / \mathrm{cm}^{3}$; the thin bed is limestone with porosity of $40 \%$ saturated with fresh water and density of $2.026 \mathrm{~g} / \mathrm{cm}^{3}$. The thickness $H$ of the thin bed is set to $36 \mathrm{~cm}, 45 \mathrm{~cm}$ and $54 \mathrm{~cm}$ and the thickness $H_{C}$ of casing is set to $0,1.5 \mathrm{~cm}$ and $3.0 \mathrm{~cm}$ respectively. The radioactive source is placed at the point $(9,0,54)$ and the detector with a long spacing of $40 \mathrm{~cm}$ is placed at the point $(9$, $0,94)$. We calculated only for the long spacing detector in this paper. Curves of detector count changing with the longitudinal position of the thin bed were obtained when the thin bed moved from bottom to top of the model gradually (Fig. 2).

Fig. 2 shows that with the thin bed moving upward, the detector count increases gradually, reaches a maximum and then declines. The detector count curve is symmetrical and its half-width is close to the thickness of the thin bed. The count maximum appears at the point $(9,0,74)$, that is nicely the midpoint between source and long spacing detector, which proves theoretically that the sensitive position of density logging is the midpoint between source and long spacing detector. Fig. 2 also shows that when the thickness of thin bed is fixed, the thicker the casing is, the smaller the detector

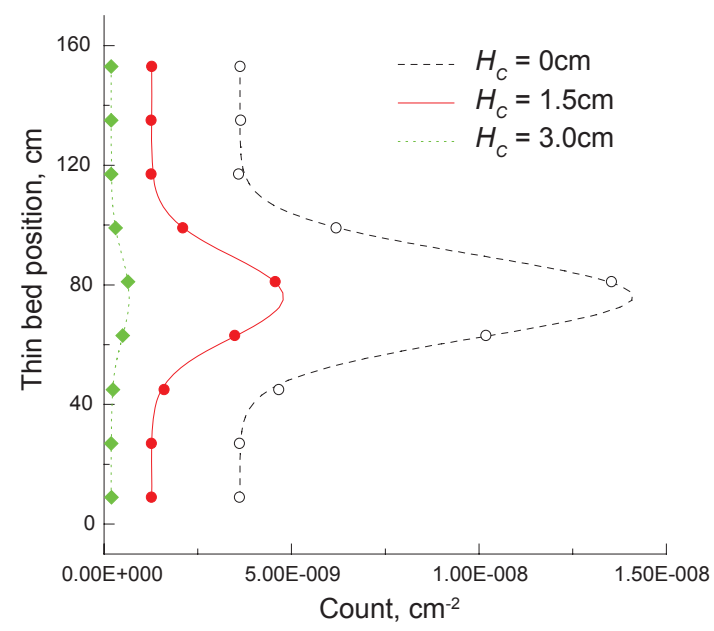

(a) $H=36 \mathrm{~cm}$

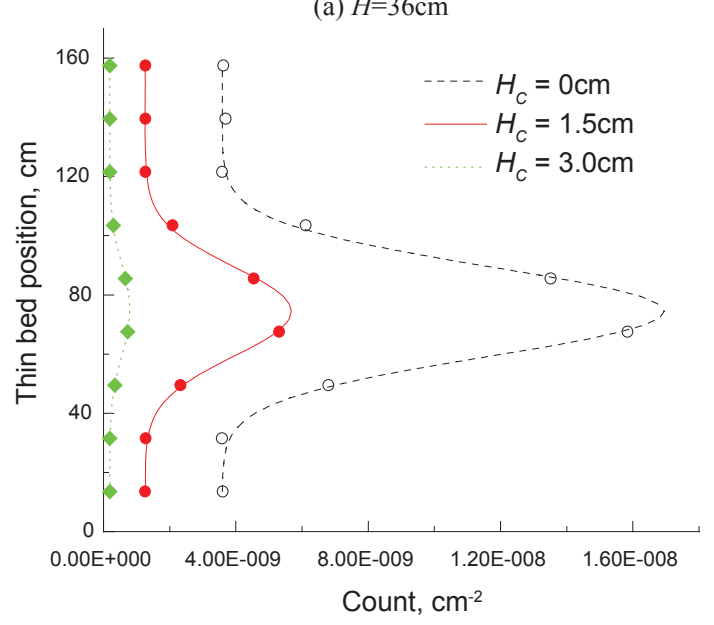

(b) $H=45 \mathrm{~cm}$

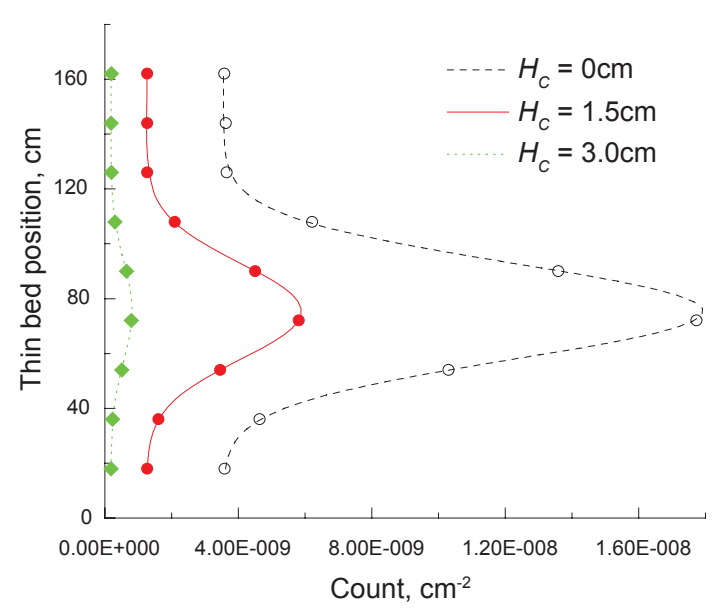

(c) $H=54 \mathrm{~cm}$

Fig. 2 Responses of thin bed location at different casing thicknesses

count is. That is to say, the casing will make statistical error increase and weaken the thin bed resolution of density logging. Therefore, appropriate casing thickness must be selected and correction for casing must be done in density logging. The responses of a thin bed with a high density are opposite to those of a thin bed with a low density.

\subsection{Responses of thin bed thickness}

The thickness $H_{C}$ of casing is $1.5 \mathrm{~cm}$ and the thickness $H$ of thin bed is designed as $18 \mathrm{~cm}, 27 \mathrm{~cm}, 33 \mathrm{~cm}, 60 \mathrm{~cm}$ and $72 \mathrm{~cm}$. The longitudinal position of the thin bed with a low density is fixed. When the tool moved from bottom to top of the model, the responses of thin bed thickness for long spacing detector were obtained as shown in Fig. 3.

Fig. 3 shows that detector count increases gradually with increasing thin bed thickness. When the thin bed thickness reaches a specific value, the detector count will increase slowly and then level off with further increasing thin bed thickness. The responses of thin bed thickness can be expressed as follows:

$$
\Delta \rho=K\left(1-e^{-r h}\right)
$$

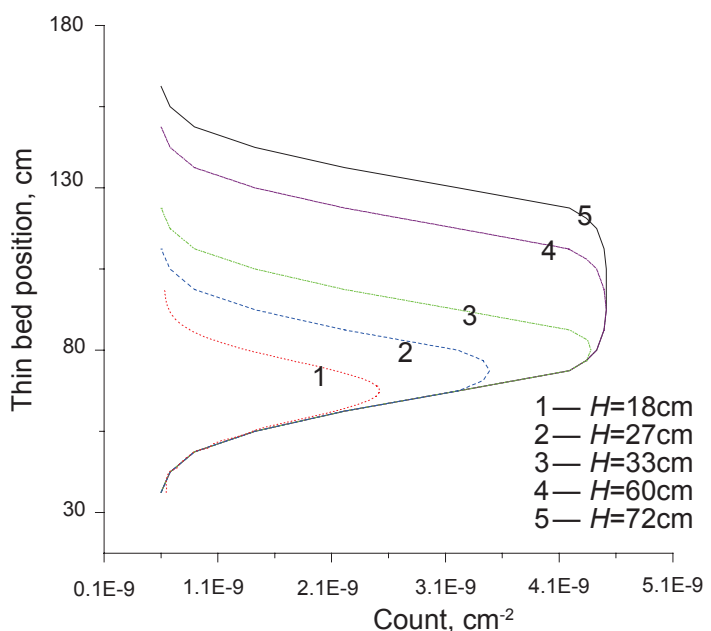

Fig. 3 Detector count curves changing with thin bed thickness 
where, $\Delta \rho$ is the change of density resulting from the thin bed; $K$ is a constant; $r$ is a positive coefficient related to the density tool construction.

\subsection{Influence of adjacent formation}

In the calculation, two thin beds with thickness $H$ of $36 \mathrm{~cm}$ and $72 \mathrm{~cm}$ are fixed one at a time at the midpoint of the model $(9,0,108)$. When the tool moved upward from the bottom of the model, the results were obtained as shown in Fig. 4.

Fig. 4 shows that count curves are asymmetric, and the counts below are bigger than those above. The reason is that the material outside of the model is supposed to be ideal shielding, that is to say, a formation with infinite density is placed at the bottom of the model. The photons emitted to the formation are reflected, which results in a high detector count. The influence of adjacent formation is greater with decreasing casing thickness.

In actual logging, the influence of adjacent formation can be ignored because there are no formations with infinite density, so the count curves are symmetrical.

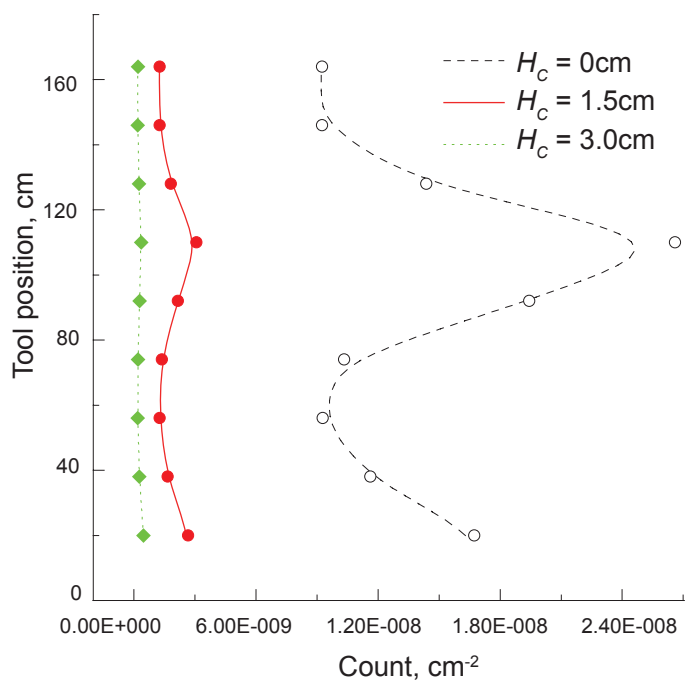

(a) $H=36 \mathrm{~cm}$

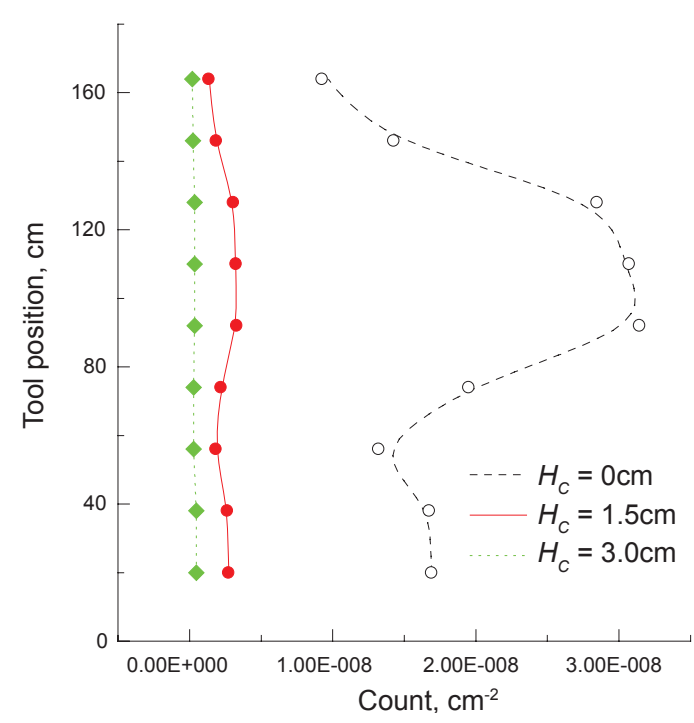

(b) $H=72 \mathrm{~cm}$

Fig. 4 Influence of adjacent formation

\section{Corrections for dual influence of thin bed and casing}

For the SLDT tool (Stoller et al, 1997), two compensated density tools can be formed by using the long detector and the short detector or the middle detector and the short detector because SLDT tool has three detectors which are long, short and middle, respectively. Thus, the traditional compensated density method for mud cake can be used to compensate the influence of the casing. The compensated density value $\rho_{\mathrm{bL}}$ from the long detector compensated by the short detector and $\rho_{\mathrm{bM}}$ from the middle detector compensated by the short detector can be obtained. The formation density $\rho_{\mathrm{b}}$ can be taken as the average of $\rho_{\mathrm{bL}}$ and $\rho_{\mathrm{bM}}$.

To study the influence and correction of the thin bed and casing, the casing thickness is set to be $1.0 \mathrm{~cm}$, long spacing is $40 \mathrm{~cm}$, middle spacing is $28 \mathrm{~cm}$, and short spacing is $12 \mathrm{~cm}$. The calculation result is shown in Fig. 5. $\Delta \rho$ is the change of density resulting from the thin bed thickness $H$ and $\Delta \rho_{\max }$ is the maximum change of density.

Fig. 5 shows that the three changing curves produce three points of intersection, and the whole area of the figure can be divided into four parts $\mathrm{A}, \mathrm{B}, \mathrm{C}$ and $\mathrm{D}$.

In the area $\mathrm{A}$, there is only casing that influences long spacing, middle spacing and short spacing counts, thus, $\rho_{\mathrm{L}}>\rho_{\mathrm{M}}>\rho_{\mathrm{S}}$. In this situation, the traditional compensated density method for mud cake can be used to correct for the influence of the casing.

In the area B, the long spacing count is influenced by both the casing and the thin bed, and the middle or short counts are only influenced by the casing, thus, $\rho_{\mathrm{L}}<\rho_{\mathrm{M}}>\rho_{\mathrm{S}}$. In this situation, the formation density can be obtained from $\rho_{\mathrm{M}}$ corrected for the effect of the casing.

In the area $\mathrm{C}$, the long spacing and middle spacing counts are influenced by both the casing and the thin bed, and the short count is only influenced by the casing, thus, $\rho_{\mathrm{L}}<\rho_{\mathrm{S}}<\rho_{\mathrm{M}}$. Formation density can be obtained from $\rho_{\mathrm{M}}$ corrected by the thin bed and casing. The equation $\Delta \rho_{\mathrm{ML}}=\rho_{\mathrm{M}}-\rho_{\mathrm{L}}$ can be used to correct the thin bed influence for $\rho_{\mathrm{M}}$ and the equation $\Delta \rho_{\mathrm{MS}}=\rho_{\mathrm{M}}-\rho_{\mathrm{S}}$ can be used to correct the casing influence for $\rho_{\mathrm{M}}$.

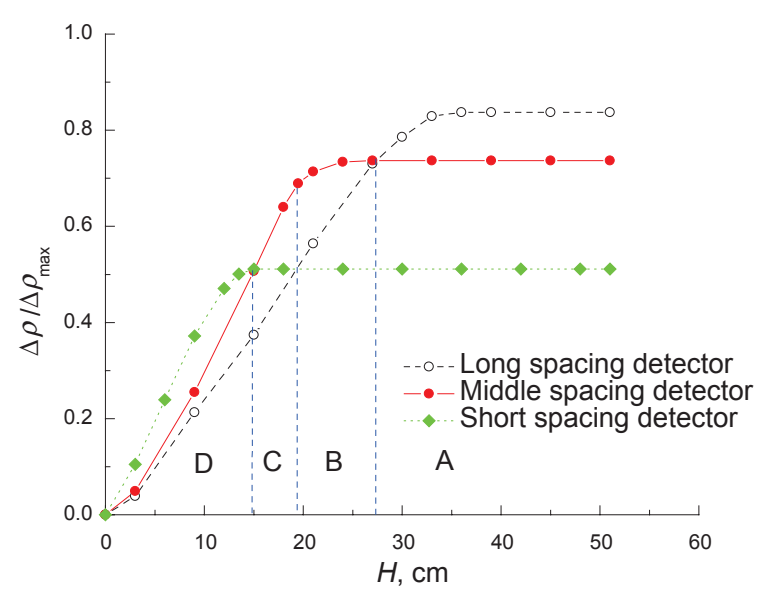

Fig. 5 Density curves changing with thin bed thickness 
In the area $\mathrm{D}$, this situation can be ignored because the thin bed thickness is too small.

\section{Conclusions}

1) The response curves from the thin bed with changing vertical location in the calculation model are symmetrical, and the half-width is close to the thickness of the thin bed. With increasing casing thickness, the detector count decreases, statistical error increases and the thin bed resolution of the density logging is reduced.

2) The detector count increases gradually with increasing thin bed thickness. When the thin bed thickness reaches a specific value, the detector count will level off with further increasing thin bed thickness.

3) The influence of adjacent formations on density logging results can be ignored.

4) A three-detector density tool can be used to correct the dual influences of the thin bed and the casing.

\section{References}

Bellman K, Bittner S, Gupta A, et al. Evaluating and monitoring reservoirs behind casing. Oilfield Review. 2003. 4(2): 3-9

Cosentine L and Spotti G. Reevaluation of hydrocarbon reserves in old fields through cased hole interpretation: a new approach. Society of Professional Well Logging Analysts, 28th Annual Logging Symposium. SPE-22345. 1992. 167-175

Ellis D, Lüling M G, Markley M E, et al. Cased-hole formation-density logging-some field experience. Society of Professional Well Logging Analysts, 45th Annual Logging Symposium. 2004. Paper G: $1-14$

Li G, Wang K X, Liu J X, et al. Acoustoelasticity theory, numerical analysis and practical example of the cased hole with stress concentration by cross-dipole acoustic logging. Chinese Journal of Geophysics. 2006. 49(1): 295-305 (in Chinese)

Luo L, Yao S X, Meng Y F, et al. Evaluation of array sonic logging effects in cased holes. Natural Gas Industry. 2006. 26(8): 50-52 (in Chinese)

Moake G L. Design of a cased-hole-density logging tool using laboratory measurements. Society of Petroleum Engineers, 73rd Annual Technical Conference and Exhibition: New Orleans LA. SPE-49226. 1998. 565-580

Qiao W X and Che X H. The effects of casing diameter on acoustic log in cased-borehole. Well Logging Technology. 2005. 29(4): 305-307 (in Chinese)

Quint E. Monitoring contact movement during depressurization of the Brent field. Society of Petroleum Engineers, Offshore Europe Conference. SPE-56951. 1999. 1-14

Shi X Q, Zhang X M and Xiong W J. Acquisition and application of acoustic imaging logging data in casing hole. Petroleum Instruments. 2006. 20(6): 71-73 (in Chinese)

Stoller C, Darling H L, Dasgupta T, et al. Density logging in slim holes with a novel array density tool. SPE-38650. 1997. 69-78

Tan H Q, Peng C C, Li W H, et al. Application of cased-hole formation resistivity $\log$ in monitoring distribution of remaining oil. Petroleum Geology and Recovery Efficiency. 2003. 10(4): 69-70 (in Chinese)

Wolcott D S and Vittachi A. Through casing formation density measurements using a gamma-gamma density tool. Society of Professional Well Logging Analysts, 2nd International Well Logging Symposium Transactions. 1994. 279-295

Wu W S and Huang L J. Monte Carlo simulation of three-detector density logging. Chinese Journal of Geophysics. 2004. 47(1): 164-170 (in Chinese)

Wu W S and Xiao L Z. Monte Carlo numerical simulation of response characteristics of density logging in cased hole. Journal of China University of Petroleum. 2007a. 31(1): $45-48$ (in Chinese)

$\mathrm{Wu} \mathrm{W}$ S and Xiao L Z. Estimation for casing thickness with litho-density logging in cased holes. Nuclear Techniques. 2007b. 30(3): 185-188 (in Chinese)

Zhou Y Q, Wang X M and Chen D H. Study of numerical simulation on amplitude attenuation of first arrivals in cased-hole acoustic logging. Well Logging Technology. 2007. 31(4): 321-326 (in Chinese)

(Edited by Hao Jie) 